\title{
Maternal and community factors associated with postnatal care checkups in Ethiopia: A multi-level analysis
}

Afework Tadele ( $\sim$ afatadele@gmail.com )

Jimma University College of Public Health and Medical Sciences https://orcid.org/0000-0001-5682-

6117

Masrie Getinet

Jimma University

\section{Research}

Keywords: Postnatal care, multilevel, DHS, Ethiopia

Posted Date: June 10th, 2020

DOl: https://doi.org/10.21203/rs.3.rs-34095/v1

License: (c) (1) This work is licensed under a Creative Commons Attribution 4.0 International License.

Read Full License 


\section{Abstract}

Background Maternal mortality remained a public health issue, especially in developing countries. Although the first two days after birth was a critical time in which the highest maternal death recorded, it was the most neglected period of maternal health services. Therefore, this study aims to determine the maternal and community-level factors of postnatal check-ups in Ethiopia Methods Demographic and Health Survey (DHS) in 2016 was utilized. A total of 3,948 women aged 15-49 giving birth in the two years before the survey were included. The response variables were post-natal check-ups in the first two days after birth, dichotomized into no check-ups in the first two days and check-ups within two days after giving birth. The explanatory variables were individual maternal characteristics such as education, household wealth, perceived distance to a health facility to get medical help, employment status, antenatal care (ANC), delivery by cesarean section, birth order and place of delivery, and selected community characteristics such as community literacy, community socioeconomic status, community ANC coverage, community perception of distance to a health facility, and regional states. A multi-level mixed-effects logistic regression model was employed. Result Only $17 \%$ of the women had a postnatal check-up within 2 days of giving birth in Ethiopia. Institutional delivery AOR 2.14 [95\% C.I 1.70, 2.0] and giving birth by cesarean section AOR $1.66[95 \% \mathrm{Cl} 1.10,2.50]$ were found to be maternal factors, whereas administrative regions(Oromia 69\%, Somali 56\%, Benishangul 55\%, SNNPR 43\%, Gambela 66\%, Afar 50\% and Dire Dawa $55 \%$ which less likely to utilize postnatal care utilization as compared to Addis Ababa city administrative area), Higher community-level wealth AOR 1.44 [95\% C.I 1.08, 1.2], ANC coverage AOR 1.52 $[95 \%$ C.I 1.19, 1.96] and perceived distance of the health facility as a big problem AOR $0.78[95 \%$ C.I 0.60 , 0.99] were the community factors associated with postnatal check-ups in Ethiopia. Conclusion Both maternal factors and community factors are found to be a significant association with postnatal care services utilization, however, based on the ICC maternal factors prevail the community-level factors. Increasing access to postnatal care services to the remote areas of Ethiopia was recommended.

\section{Plain English Summary}

This study examines maternal and community-level factors associated with postnatal care checkups in Ethiopia, through a multilevel-mixed effects analysis of the 2016 Ethiopia Demographic and Health Survey.

A multilevel approach is decisive to understand both maternal and community-level factors influencing postnatal care checkups. The study finds that less than one in five women had a postnatal check-up within two days of giving birth in Ethiopia. The factors that most influence this were found to be a maternal factor (place of delivery and cesarean section delivery), and community factors (administrative regions, community wealth, ANC coverage, and perceived distance of the health facility as a big problem). We believe that our study makes a significant contribution to the literature, because it provides a multivariate analysis of the complex set of factors influencing post-natal check-ups has been studied in an isolated fashion thus far. This study is also significant as it provides cogent policy recommendations for the design and implementation of economic and non-economic interventions into maternal health. 


\section{Background}

Globally, approximately about 810 women die from preventable causes related to pregnancy and childbirth a day; with $94 \%$ of the death occur in low and lower-middle-income (LMIC) countries [1]. Evidence revealed that most of the maternal death recorded in the early postnatal period. For instance more than $80 \%$ of the mortality in the first fourteen days after birth, and more than $60 \%$ in the post-natal period in both developing countries and the United States [2]. Yet, this is the most neglected period in the provision of quality care [3].

According to the World Health Organization(WHO), the postnatal period begins immediately after childbirth and lasts six weeks [4]. It is an essential element across the continuum of care in the maternal and child health care services, and serve as a gateway for family planning services. Woman and her partner/family require more information than they usually receive on the care of the baby and mother within the first week after childbirth, to stay safe from maternal and neonatal complications [5].

Although there is a good improvement in maternal and child health care services coverage recently, less than one in five women received a postnatal check within the first two days of birth in Ethiopia [6]. The experiences and expectations of women and their families and barriers to the uptake of services and/or access to services also should be considered for improving postnatal care services in the country [4].

Previous work in Ethiopia has only focused on identifying the association of individual/household characteristics like education, wealth [7, 8], residence, occupation, antenatal care (ANC) follow-up, institutional delivery, [9-15], and distances from health institutions [16] with postnatal checkups. Although this approach is interesting, it fails to take into account the community-level variables, postnatal care clients were living in a community with different social contexts. A multilevel approach is decisive to understand both maternal and community-level factors, however, no studies in Ethiopia considered such analysis for postnatal checkups. Therefore, the aim of this study is to estimate the extent of maternal and community factors associated with postnatal checkups in Ethiopia.

\section{Methods}

\section{Study setting}

Ethiopia is the second populous country in Africa next to Nigeria bordered by Eretria, South Sudan, Sudan, Djibouti, and Somalia with a total of more than one hundred ten million people [17]. The country has a decentralized three-tier health care system named as primary, secondary, and tertiary care. At the primary level of health care, there were district hospitals, health centers, and their satellite health posts; the secondary level health cares are general hospitals, and the tertiary level health care are specialized hospitals[18]. Administratively, Ethiopia is divided into nine geographical regions (Tigray, Afar, Amhara, Oromia, Somali, Benishangul-Gumuz, SNNPR, Gambella, and Harari) and two administrative cities, Addis Ababa and Diredawa. The 2016 EDHS was a population-based cross-sectional study conducted from January 18,2016 , to June 27,2016 , across the country [6]. 


\section{Data Source}

The dataset utilized in this study was obtained from the DHS program accessed from http://dhsprogram.com/data/. The DHS program office gave an authorization letter to access the 2016 EDHS, which is the fourth comprehensive survey. The 2016 EDHS sample was selected in two stages. In the first stage, a total of 645 clusters (202 in urban and 443 in rural) were selected randomly proportional to the household size from the sampling strata, and in the second stage, 28 households per cluster were selected using systematic random sampling[6]. Representative samples of 18008 households were selected and 16, 650 households were interviewed in 2016 EDHS. For an individual interview, 16, 583 eligible women were identified from the interviewed household. Interviews were completed with 15,683 women aged 15-49 years [18]. In this study, among women aged 15-49 years, 3984 gave birth in the two years before the survey were included.

\section{Study variables definitions and measurements}

\section{Dependent variable}

The outcome variable was categorized as "use of postnatal care coded as 1" and "do not use of postnatal care coded as 0 " within two days after birth.

\section{Independent variables}

The independent variables for postnatal care use were broadly classified into individual/household characteristics and community-level variables in line with a multilevel analytic approach.

\section{Maternal variables}

Educational level of women, household wealth index, perceived distance to a health facility to get medical help, employment status of women's, number of ANC visits during pregnancy, delivery by cesarean section, birth order, and place of delivery were included as individual-level variables.

\section{Community-level variables}

Aggregated variables at the community level based on the individual information and then the aggregated values were classified as low and high if the median values or the proportions of the clusters were below and above the national value respectively. Based on this, community-level wealth index, community-level ANC coverage, community-level women's education, perceived distance to a health facility to get medical help at the community level were considered as community-level variables. These variables were selected based on their significance in previous studies [19-21].

\section{Region}


The EDHS sample was collected from nine regions and two administrative cities. We used these administrative boundaries as community-level factors.

\section{Place of residence}

It was classified as rural (coded as 1 ) and urban (coded as 0 ), considered as a community level factor.

\section{Community-level education of women}

The median value of educational attainment at the national level was 5 years. Thus, the median value of the aggregated clusters below 5 was classified as low education (coded as 0 ) of women and the median value of the aggregated clusters 5 and more were classified as high education (coded as 1 ) of women.

\section{Community-level wealth}

Similarly, the median value of the wealth index at the national level was 3 . Then, the aggregated clusters were classified as low wealth (coded as 0 ) and high wealth (coded as 1 ) by considering the national value as a cut-off point.

\section{Perceived distance to a health facility at the community level}

At the national level the proportion of perception of distance to a health facility to get medical help as a big problem was 0.45 . So, clusters were classified as low perception (coded as 0 ) and high perception (coded as 1 ) using the national proportion as a cut-off point after aggregated of it.

\section{Community-level ANC visit}

The median value of ANC visit at the national level was 3. Hence, the median value of the cluster less than 3 ANC visits were classified as low (coded as 1) and greater than or equal to 3 ANC visits were classified as high (coded as 1) after aggregated the ANC visit.

\section{Data analysis}

Two-level mixed-effects logistic regression analyses were employed using STATA version 14. Since 2016 EDHS data was hierarchical, i.e., individuals (women) were nested in households, and households were nested in the cluster. The unit of analysis for the characteristics of community-level factors was the cluster. For this study, we included 645 clusters in which all the women whose most recent birth was within two years preceding the survey resides.

First, bi-variable two-level mixed-effects logistic regression analyses were done to assess the association between the independent variables and the dependent variable of the study. The overall categorical variables with a $p$-value of $<0.25$ at the bivariate two-level mixed-effect logistic regression analysis were included in the final model of the multivariable two-level mixed-effect logistic regression model in which odds ratio with $95 \%$ confidence intervals were estimated to identify the independent variables of 
postnatal checkups. P-values less than 0.05 were employed to declare statistical significance. Fixed effect and random effect were calculated to assess the individual and cluster variations respectively. Moreover, the frequency table was displayed for the individual and community level variables. All analysis was done on weighted data.

In this analysis four models are displayed, null model (model containing no factors), a model I (containing only individual factors), model II (containing only community factors), and model III (both individual and community-level factors). The fitted model was:

$$
\log \left[\frac{\pi_{i j}}{1-\pi_{i j}}\right]=\beta_{0}+\beta_{1} \mathrm{X}_{1 i j}+\cdots \beta_{n} \mathrm{X}_{n i j}+u o_{j}+e_{i j}
$$

Where
$\checkmark \pi_{i j}$ is the probability of women who delivered at the health facility
$\checkmark 1-\pi_{i j}$ the probability of not delivered at the health facility
$\checkmark \beta_{0}$ is $\log$ odds of the intercept
$\checkmark \beta_{1} \ldots \beta_{n}$ are the amount of effect by the individual and community-level variables
$\checkmark \mathrm{X}_{1} \ldots \mathrm{X}_{n}$ are the independent variables at individual and community level
$\checkmark u o_{j}$ is the random error at community(cluster) and
$\checkmark e_{i j}$ is the random error at the individual level.

The intra-class correlation (ICC) was calculated as the proportion of the between cluster variation in the total variation:

$$
I C C=\frac{\operatorname{Var}\left(u_{o j}\right)}{\operatorname{Var}\left(u o_{j}\right)+\pi^{2} / 3}
$$

Where,

$\checkmark \operatorname{Var}\left(u_{o j}\right)$ is the community (cluster) level variance.

$\checkmark \pi^{2} / 3$ is the standard logistic distribution, that is, the assumed household variance component, which is $\pi^{2} / 3 \approx 3.29$.

The variability on the odds of institutional delivery explained by successive models was calculated by Proportional Change in Variance (PCV) as: 


$$
P C V=\frac{V_{e}-V_{m i}}{V e},
$$

Where,

$\checkmark \quad V_{e}$ is the variance in institutional delivery in the null model.

$\checkmark \quad V_{m i}$ the variances in the successive models.

\section{Results}

Maternal characteristics of the respondents

The majority (61.09\%) of the women of reproductive age in Ethiopia who gave birth in the two years preceding the survey did not attend formal education. More than seventy-five percent of the women were unemployed. Still, there is a great problem of access to a health facility in Ethiopia as the majority (61.43\%) of the women's perceived distance to a health facility to get medical help was a big problem. Regarding maternal health services in the last two years, only $32.62 \%$ percent of the women attended four and more ante-natal care and $35.6 \%$ percent gave birth in a health facility(Table 1$)$. 
Table 1

Maternal variables of women aged 15-49 giving birth in the 2 years in Ethiopia $(n=$ 3948)

\begin{tabular}{|c|c|c|c|}
\hline Individual/household variables & Categories & Frequency & $\%$ weighted \\
\hline \multicolumn{4}{|l|}{ Educational level of women } \\
\hline & No education & 2373 & 61.09 \\
\hline & Primary & 1086 & 30.34 \\
\hline & Secondary & 323 & 5.83 \\
\hline & Higher & 166 & 2.74 \\
\hline \multicolumn{4}{|l|}{ Wealth index } \\
\hline & Poorest & 1417 & 23.92 \\
\hline & Poorer & 662 & 22.06 \\
\hline & Middle & 558 & 20.93 \\
\hline & Richer & 496 & 18.53 \\
\hline & Richest & 815 & \\
\hline \multicolumn{3}{|c|}{ Perceived distance to a health facility to get medical help } & 14.55 \\
\hline & Not a big problem & 1779 & 38.57 \\
\hline & Big problem & 2169 & \\
\hline \multirow[t]{3}{*}{ women's employment status } & & & 61.43 \\
\hline & No & 2958 & 75.23 \\
\hline & Yes & 990 & 24.77 \\
\hline \multicolumn{4}{|l|}{ Number of ANC visit } \\
\hline & $<4$ & 2527 & 67.38 \\
\hline & $4^{+}$ & 1421 & \\
\hline \multirow[t]{3}{*}{ Delivery by cesarean section } & & & 32.62 \\
\hline & No & 3818 & 97.4 \\
\hline & Yes & 130 & 2.60 \\
\hline \multirow[t]{2}{*}{ Place of delivery } & Home & 2382 & 64.78 \\
\hline & Health facility & 1566 & 35.22 \\
\hline
\end{tabular}

Postnatal checkups in Ethiopia 
Only $17 \%$ of the respondents were utilized postnatal checkups with two days among the respondents in Ethiopia during the study period (Fig. 1).

Community-level characteristics of the respondents

More than eighty-eight percent of the clusters were from rural areas of Ethiopia. While sixty percent of them were classified under higher community-level wealth status. There is also about $75 \%$ community level of antenatal care coverage and women's unemployment status revealed. One in three clusters perceived the distance to Health facility to get medical help at the community level is a big problem (Table 2). 
Table 2

Community-level variables of women aged 15-49 giving birth in the 2 years before the survey $(n=3948)$

\begin{tabular}{|c|c|c|c|c|}
\hline Community-level variables & Categories & $\mathrm{n}$ & Unweighted \% & Weighted \% \\
\hline \multirow{11}{*}{$\begin{array}{l}\text { Administrative } \\
\text { regions }\end{array}$} & Tigray & 409 & 10.4 & 6.83 \\
\hline & Afar & 379 & 9.6 & 1.00 \\
\hline & Amhara & 365 & 9.2 & 18.27 \\
\hline & Oromia & 612 & 15.5 & 45.10 \\
\hline & Somali & 521 & 13.2 & 4.21 \\
\hline & Benishangul & 313 & 7.9 & 1.03 \\
\hline & SNNPR & 477 & 12.1 & 20.40 \\
\hline & Gambela & 264 & 6.7 & 0.24 \\
\hline & Harari & 221 & 5.6 & 0.23 \\
\hline & Dire Dawa & 182 & 5.2 & 2.30 \\
\hline & Addis Ababa & 205 & 4.6 & 0.41 \\
\hline \multirow[t]{2}{*}{ Place of residence } & Urban & 767 & 19.4 & 11.34 \\
\hline & Rural & 3181 & 80.6 & 88.66 \\
\hline \multirow[t]{2}{*}{ Community-level wealth } & low & 2017 & 51.1 & 40.33 \\
\hline & High & 1931 & 48.9 & 59.67 \\
\hline \multicolumn{5}{|c|}{ Community-level ANC coverage } \\
\hline & low & 2687 & 68.1 & 74.95 \\
\hline & High & 1261 & 31.9 & 25.05 \\
\hline \multicolumn{5}{|c|}{ Community-level women's employment } \\
\hline & low & 2854 & 72.3 & 75.49 \\
\hline & High & 1094 & 27.7 & 24.51 \\
\hline \multicolumn{5}{|c|}{ Community-level women's education } \\
\hline & low & 1874 & 47.5 & 61.43 \\
\hline & high & 1541 & 39.0 & 38.57 \\
\hline \multicolumn{5}{|c|}{$\begin{array}{l}\text { Perceived distance to Health facility } \\
\text { to get medical help at the community level }\end{array}$} \\
\hline
\end{tabular}




\begin{tabular}{|lllll|}
\hline Community-level variables & Categories & $\mathbf{n}$ & Unweighted \% & Weighted \% \\
\hline & Not a big problem & 1506 & 38.1 & 30.02 \\
& Big problem & 2442 & 61.9 & 69.98 \\
\hline
\end{tabular}

\section{Multi-variable Multilevel Analyses Result}

A two-level mixed-effects logistic regression model was used to analyze the effects of community characteristics and women's individual-level factors in postnatal care services utilization in Ethiopia.

As depicted in the empty model, $36.5 \%$ of the variations in postnatal checkups could be attributed to community characteristics. The value of the log-likelihood result consistently decreased as fitted models progressed from the empty model to Model 1, Model 2, and Model 3 indicating that the fitted models were a better fit to the data (Table 5). The higher the ICC, the more relevant were the community characteristics for understanding individual variation in postnatal checkups for mothers. Accordingly, the combined model of maternal, and community factors was selected for determining postnatal checkups in Ethiopia.

\section{Maternal factors associated with postnatal checkups in Ethiopia}

The details of the effect sizes of both individual and community-level factors on the odds of postnatal care service utilization are described in Tables 3 and 4 . Delivery by cesarean section was independently and significantly associated with postnatal care utilization.

After adjusting for individual and community-level factors, the odds of using postnatal care was 1.66 times OR $1.66(95 \% \mathrm{Cl} 1.10,2.50)$ higher among women gave birth by cesarean section compared to their counterparts. Similarly, women who gave birth at health facilities were twice higher odds of using postnatal care OR $2.14(95 \% \mathrm{Cl} 1.70,2.70)$ as compared to those delivered at home (Table 3). 
Table 3

Multilevel mixed-effect logistic regression results of maternal and community-level factors associated with timely use of postnatal care in Ethiopia, 2016 EDHS.

\begin{tabular}{|lllll|} 
Variables/ & $\begin{array}{l}\text { Null } \\
\text { model }\end{array}$ characteristics & Model I & Model II & Model III \\
\cline { 3 - 5 } & & $\begin{array}{l}\text { Maternal/household } \\
\text { characteristics }\end{array}$ & $\begin{array}{l}\text { Community-level } \\
\text { characteristics }\end{array}$ & $\begin{array}{l}\text { Maternal and community- } \\
\text { level characteristics }\end{array}$ \\
\cline { 2 - 4 } & OR $(95 \% \mathrm{C} \mathrm{I})$ & OR $(95 \% \mathrm{C} \mathrm{I})$ & OR $(95 \% \mathrm{C} \mathrm{I})$
\end{tabular}

Educational level of women

$\begin{array}{lll}\text { No education (Ref) } & 1 & \\ \text { Primary } & 0.97(0.78,1.21) & 0.92(0.73,1.14) \\ \text { Secondary } & 1.15(0.84,1.59) & 1.04(0.75,1.46) \\ \text { Higher } & 1.55(1.02,2.34) \text { * } & 1.40(0.92,2.14)\end{array}$

Household

wealth

Poorest ${ }^{(\text {ref })} 1$

$\begin{array}{lll}\text { Poorer } & 1.38(1.03,1.85) * & 1.14(0.83,1.56) \\ \text { Middle } & 1.40(1.03,1.90) * & 0.97(0.68,1.38) \\ \text { Richer } & 1.43(1.05,1.97) * & 0.99(0.68,1.43) \\ \text { Richest } & 2.59(1.90,3.53) * \star \star & 1.29(0.82,2.01)\end{array}$

Perceived distance to Health

facility to get medical help

Not big problem ${ }^{(\text {ref })} \quad 1$

$\begin{array}{lll}\text { Big problem } \quad 0.75(0.62,0.91) * * & 1.0(0.79,1.26)\end{array}$

Number of ANC visit during

pregnancy

$<4$ visits $^{(\text {ref) }} \quad 1$

$4^{+}$Visit $\quad 1.26(1.04,1.53)$ * $\quad 0.95(0.76,1.18)$

Delivery by cesarean section

No ${ }^{(\text {ref })} \quad 1$

${ }^{*} \mathrm{P}<0.05$, ** $\mathrm{P}<0.001$, ***P $<0.0001$ 


\begin{tabular}{|c|c|c|c|c|}
\hline \multirow{3}{*}{$\begin{array}{l}\text { Variables/ } \\
\text { characteristics }\end{array}$} & \multirow{3}{*}{$\begin{array}{l}\text { Null } \\
\text { model }\end{array}$} & Model I & Model II & Model III \\
\hline & & $\begin{array}{l}\text { Maternal/household } \\
\text { characteristics }\end{array}$ & $\begin{array}{l}\text { Community-level } \\
\text { characteristics }\end{array}$ & $\begin{array}{l}\text { Maternal and community- } \\
\text { level characteristics }\end{array}$ \\
\hline & & OR $(95 \% \mathrm{C} \mathrm{I})$ & OR $(95 \% \mathrm{C} \mathrm{I})$ & OR $(95 \% \mathrm{C} \mathrm{I})$ \\
\hline Yes & & $1.76(1.18,2.63) * \star$ & & $1.66(1.10,2.50)$ * \\
\hline \multicolumn{5}{|l|}{$\begin{array}{l}\text { Place of } \\
\text { delivery }\end{array}$} \\
\hline \multicolumn{2}{|c|}{ Not at a health facility } & 1 & & \\
\hline \multicolumn{2}{|l|}{ Health facility } & 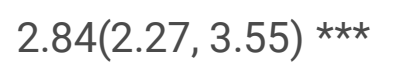 & & 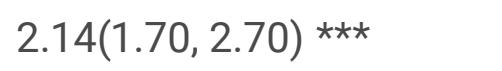 \\
\hline$* P<0.05, * * P$ & 001, ** & $<0.0001$ & & \\
\hline
\end{tabular}

\section{Community factors associated with postnatal checkups in Ethiopia}

There is significant administrative regional variation in postnatal care use. The conspicuous observation to emerge from the data comparison was in Oromia $69 \%$, Somali $56 \%$, Benishangul $55 \%$, SNNPR $43 \%$, Gambela $66 \%$, Afar $50 \%$ and Dire Dawa $55 \%$ which less likely to utilize postnatal care utilization as compared to Addis Ababa city administrative area. While there is no significant difference between residents of Harari city, Amhara regional state, and Tigray regional state as compared to Addis Ababa city. Community-level wealth and antenatal care coverage were also found to be significant determinants of postnatal care utilization. Community-level wealth was I.4 times OR $1.44(95 \%$ C.I 1.08, 1.2) and community level antenatal care coverage was 1.5 times OR $1.52(95 \%$ C.I 1.19, 1.96) more likely to use postnatal care utilization. Perceived community level distance of health facility as a big problem was found to be highly significant determinants of postnatal care. A community who perceived the distance to a health facility as a big problem were $22 \%$ less likely OR $0.78(95 \%$ C.I $0.60,0.99)$ to utilize postnatal care as compared to their counterparts (Table 4). 
Table 4

Multilevel mixed-effect logistic regression results of individual and community level predictors of postnatal care in Ethiopia, 2016.

\begin{tabular}{lllll}
$\begin{array}{l}\text { Variables/ } \\
\text { characteristics }\end{array}$ & $\begin{array}{l}\text { Null } \\
\text { model }\end{array}$ & Model I & Model II & Model III \\
\cline { 3 - 5 } & & $\begin{array}{l}\text { Maternal } \\
\text { characteristics }\end{array}$ & $\begin{array}{l}\text { Community-level } \\
\text { characteristics }\end{array}$ & $\begin{array}{l}\text { Maternal and community- } \\
\text { level characteristics }\end{array}$
\end{tabular}

Administrative regions

Tigray

Afar

Amhara

Oromia

Somali

Benishangul

SNNPR

Gambela

Harari

Dire Dawa

Addis Ababa ${ }^{\text {(ref) }}$

Place of

residence

Urban $^{(\text {ref) }}$

Rural

Community-

level wealth

low ${ }^{(\text {ref })}$

High

Community-level ANC coverage

low ${ }^{(\mathrm{ref})}$

High

Community-level perceptions of distance to HF
$1.31(0.82,2.10) \quad 1.35(0.88,2.07)$

$0.38(0.21,0.68)$ ** $\quad 0.50(0.29,0.87)$ *

$0.49(0.29,0.83)$ ** $\quad 0.63(0.39,1.03)$

$0.24(0.14,0.42) * \star \star \quad 0.31(0.19,0.50)$ ***

$0.32(0.18,0.56)$ *** $0.44(0.26,0.73)$ **

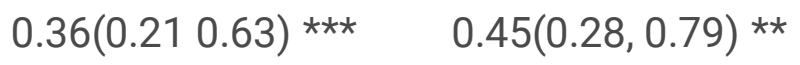

$0.47(0.29,0.78)$ ** $\quad 0.57(0.36,0.90)$ **

$0.27(0.15,0.48)$ *** $0.34(0.20,0.58)$ *

$1.06(0.62,1.80) \quad 1.10(0.68,1.79)$

$0.49(0.29,0.83)$ ** $\quad 0.55(0.34,0.89)$ *
1

$0.60(0.44,0.82) * \star \quad 0.94(0.65,1.37)$

*P $<0.05, * * P<0.001, * * * P<0.0001$ 


\begin{tabular}{|lllll|}
\hline $\begin{array}{l}\text { Variables/ } \\
\text { characteristics }\end{array}$ & $\begin{array}{l}\text { Null } \\
\text { model }\end{array}$ & Model I & Model II & Model III \\
\cline { 2 - 5 } & $\begin{array}{l}\text { Maternal } \\
\text { characteristics }\end{array}$ & $\begin{array}{l}\text { Community-level } \\
\text { characteristics }\end{array}$ & $\begin{array}{l}\text { Maternal and community- } \\
\text { level characteristics }\end{array}$ \\
\hline $\begin{array}{l}\text { Not a big } \\
\text { problem }\end{array}$ & 1 & \\
\hline Bigf & & $0.70((0.54,0.90) * \star$ & $0.78(0.60,0.99) * \star$ \\
\hline$* P<0.05, * \star P<0.001, * \star * P<0.0001$ & & \\
\hline
\end{tabular}

Table 5

Multilevel logistic regression model showing random-effects on postnatal checkups in Ethiopia.Random effects

\begin{tabular}{|lllll|}
\hline & Model 0 & Model 1 & Model 2 & Model 3 \\
\hline ICC (\%) & $36.5 \%$ & $7.1 \%$ & $6.8 \%$ & $1 \%$ \\
\hline PCV & Reference & $81 \%$ & $81.4 \%$ & $97 \%$ \\
\hline Model fitness & & & & \\
\hline Log likelihood & -1883.6 & -1736.0 & -1633.2 & -1536.0 \\
\hline
\end{tabular}

\section{Discussion}

The findings of the study are decisive in achieving SDG, the global target of reducing the maternal mortality ratio to less than 70 per 100,000 births [22]. Also, it was vital for the global strategy, aimed at ending preventable maternal mortality through enlightening predictors of inequalities in access to and quality of maternal, and newborn health care services in different clusters of the Ethiopian community [1]. Therefore, identifying maternal characters and community-level determinants of postnatal care has a great contribution in designing different interventions for improving maternal and child health.

This study found different individual and community-level determinants of postnatal care service utilization were identified. In this study, $36.5 \%$ of the total variance in the odds of postnatal care utilization was accounted for the characteristics of between-cluster variation. While $7.1 \%$ at maternal and $6.8 \%$ in community-level variation were identified. We found much higher values than a cross-sectional study in remote and poorest rural communities of Zambia in 2012, which revealed $22 \%$ and study in Nigeria 10.35\% [23], variance in the use of PNC within 48 hours were attributable to the variations across community clusters [24]. This implies the issues of equity in postnatal care services for availability and accessibility were still a great challenge for the community.

This study found that women who gave birth by cesarean section were 1.66 times higher odds of using postnatal care services within the first two days compared to those given birth by another mode of delivery. This is in good agreement with the study in rural Tanzania in 2015 revealed cesarean section 
delivery was positively associated with postnatal care use [25]. This might be women who gave birth by cesarean section stay at the facility for about two days for which they receive a postnatal check-up.

In another way, women who gave birth at the health facilities were twice more likely to utilize postnatal care as compared to those delivered at home. This substantiates previous findings in the study in different parts of Ethiopia like Tigray and SNNPR, [9-11,25] and Tanzania [25]. This might be clients who visit the health facility would have different health-seeking behaviors with those never attended health facility.

There is significant administrative regional variation in postnatal care use in Oromia, Somali, Benishangul, SNNPR, Gambela, Afar, and Dire Dawa which less likely to utilize postnatal care utilization as compared to Addis Ababa city administrative area. While there is no significant difference between residents of Harari city, Amhara regional state, and Tigray regional state as compared to Addis Ababa city. Variation in postnatal care service utilization varies was also observed in different parts of Ethiopia $[8-10,26,27]$ and West African countries [20]. There are several possible explanations for this finding, first the difference in geographic accessibility of the postnatal care services due to topography and unfavorable roads for the mothers in rural areas of Ethiopia; second, there was a difference in local cultures and beliefs in different areas of the country; third, the difference in urbanized geographical areas among different regions.

Being in the higher community level antenatal care coverage were 1.5 times more likely to utilize postnatal care services. Our findings appear to be well supported by a multilevel analysis of DHS in subSaharan Africa in 2014, which found significant associations between four or more antenatal care visits and ever breastfed with both outcomes [28]. The results point to the likelihood of information diffusion for postnatal care utilization in the community.

Being a resident of higher community-level wealth was I.4 times more likely to utilize post-natal care services. This concurs well with the study in West Africa in 2018, which revealed community-level poverty was a significant determinant of postnatal care use [20]. This would appear to indicate that a wealthy community was more probability of getting health information and reside in urban areas.

A community who perceived the distance to a health facility as a big problem were $22 \%$ less likely to utilize postnatal care as compared to their counterparts. We believe that no other authors have found that postnatal care utilization is less likely in the community who perceived the distance of health facility as a big problem. There is a good probability that community telling can influence any health care service utilization.

This study provides strong evidence in utilizing community-based representative data of DHS and the use of multilevel mixed-effects analysis which bring disaggregated data on individual characteristics and community-level determinants for designing contextual interventions. 
We are aware that our research may have three limitations. The first is findings are based on quantitative data only which cannot explore the detailed reasons in the community for low levels of postnatal care use. The second is excluding men's and other community-level significant others view, may not give fully address the community-level determinants. Lastly, the information on postnatal care provided by mothers was retrospective and those women who had given birth 2 years ago can't probably remember accurately the service they received. These limitations are evidence of the DHS women's data not inclusive of the above problems.

\section{Conclusion}

Less than one in five women utilized postnatal care in the first 2 days after birth in Ethiopia. Both maternal factors and community factors are found to be a significant association with postnatal care services utilization, however, based on the ICC maternal factors prevail the community-level factors. Increasing access to postnatal care services to the remote areas of Ethiopia was recommended.

\section{Abbreviations}

AOR: Adjusted Odds Ratio, ANC: Antenatal Care, Cl: Confidence Interval, EDHS: Ethiopian Demography and Health Survey, HF: Health Facility, HH: Household, ICC: Intra Class Correlation, MEASURE DHS: Monitoring and Evaluation to Assess and Use Results Demographic and Health Surveys, PCV: Proportional Change in Variance, PNC: Postnatal Care, SDG: Sustainable Development Goal, SNNPR: Southern Nations, Nationalities, and Peoples' Region.

\section{Declarations}

\section{Ethics approval and consent to participate:}

N/A

Consent to publish:

the data was obtained after necessary agreement to publish for this research title from DHS program database at

\section{Availability of data and materials:}

The data sets used and/or analyzed during the current study are available from the corresponding author on reasonable request.

Competing interests: 
The authors declare that they have no competing interests.

\section{Funding:}

N/A

\section{Authors' Contributions:}

AT made substantial contributions to conception, design, and in the drafting of the manuscript. MG involved the acquisition of data, analysis, and involved revising the manuscript critically for important intellectual content. All authors read and approved the final manuscript.

\section{Acknowledgments:}

We would like to acknowledge the Demographic Health Survey program office for the realizations of this finding by authorizing the data.

\section{References}

1. WHO. Maternal mortality: fact sheets; 2018.

2. Li XF, Fortney JA, Kotelchuck M, Glover LH. The postpartum period: the key to maternal mortality. International Journal of Gynecology Obstetrics. 1996;54(1):1-10.

3. (WHO) WHO. WHO recommendations on Postnatal care of the mother and newborn 2013.

4. WHO. Technical Consultation on Postpartum and Postnatal Care. 2010.

5. Kikuchi KYJ, Nanishi K, Ahmed A, Nohara Y, Nishikitani M, et al.: Postnatal care could be the key to improving the continuum of care in maternal and child health in Ratanakiri, Cambodia. 2018:1-13.

6. CentralStatisticalAgency(CSA)[Ethiopia]andICF. Ethiopia Demographic and Health Survey 2016. In: In. Addis Ababa, Ethiopia, and Rockville. Maryland: CSA and ICF; 2016.

7. Fekadu GA, Ambaw F, Kidanie SA. Facility delivery and postnatal care services use among mothers who attended four or more antenatal care visits in Ethiopia: further analysis of the 2016 demographic and health survey. BMC Pregnancy Childbirth. 2019;19(1):64.

8. Wudineh KG, Nigusie AA, Gesese SS, Tesu AA, Beyene FY. Postnatal care service utilization and associated factors among women who gave birth in Debretabour town, North West Ethiopia: a community- based cross-sectional study. BMC Pregnancy Childbirth. 2018;18(1):508.

9. Abraha TH, Gebrezgiabher BB, Aregawi BG, Belay DS, Tikue LT, Reda EB. Factors Associated with Compliance with the Recommended Frequency of Postnatal Care Services in Four Rural Districts of Tigray Region, North Ethiopia. Korean J Fam Med 2019. 
10. Abuka Abebo T, Jember Tesfaye D. Postnatal care utilization and associated factors among women of reproductive age Group in Halaba Kulito Town, Southern Ethiopia. Arch Public Health. 2018;76:9.

11. Abota TL, Atenafu NT. Postnatal Care Utilization and Associated Factors among Married Women in Benchi-Maji Zone, Southwest Ethiopia: A Community Based Cross-Sectional Study. Ethiop J Health Sci. 2018;28(3):267-76.

12. Barry D, Frew AH, Mohammed H, Desta BF, Tadesse L, Aklilu Y, Biadgo A, Buffington ST, Sibley LM. The effect of community maternal and newborn health family meetings on type of birth attendant and completeness of maternal and newborn care received during birth and the early postnatal period in rural Ethiopia. J Midwifery Womens Health. 2014;59(Suppl 1):44-54.

13. Chaka EE, Abdurahman AA, Nedjat S, Majdzadeh R. Utilization and Determinants of Postnatal Care Services in Ethiopia: A Systematic Review and Meta-Analysis. Ethiop J Health Sci. 2019;29(1):93544.

14. Tesfahun F, Worku W, Mazengiya F, Kifle M. Knowledge, perception and utilization of postnatal care of mothers in Gondar Zuria District, Ethiopia: a cross-sectional study. Matern Child Health J. 2014;18(10):2341-51.

15. Tesfaye S, Barry D, Gobezayehu AG, Frew AH, Stover KE, Tessema H, Alamineh L, Sibley LM. Improving coverage of postnatal care in rural Ethiopia using a community-based, collaborative quality improvement approach. J Midwifery Womens Health. 2014;59(Suppl 1):55-64.

16. Darega B, Dida N, Tafese F, Ololo S. Institutional delivery and postnatal care services utilizations in Abuna Gindeberet District, West Shewa, Oromiya Region, Central Ethiopia: A Community-based cross sectional study. BMC Pregnancy Childbirth. 2016;16:149.

17. WHO. Department of Economic and Social Affairs Population Division. World Population Prospects 2019.

18. Health Mo. Health sector development program IV 2010/11-2014/15. Addis Ababa, Ethiopia: Federal Democratic Republic of Ethiopia.; 2010.

19. Solanke BL, Oyinlola FF, Oyeleye OJ, Ilesanmi BB. Maternal and community factors associated with unmet contraceptive need among childbearing women in Northern Nigeria. Contraception and Reproductive Medicine 2019, 4(1).

20. Solanke BL, Amoo EO, Idowu AE. Improving postnatal checkups for mothers in West Africa: A multilevel analysis. Women Health. 2017;58(2):221-45.

21. Abate MG, areke AA. Individual and community level associatesof contraceptive use in Ethiopia: amultilevel mixed effects analysis. Archives of Public Health 2019, 77(46).

22. World Health Organization. Regional Office for the Western P: Sustainable development goals (SDGs): Goal 3. Target 3.1 : By 2030, reduce the global maternal mortality ratio to less than 70 per 100,000 live births [poster]. In.: Manila: WHO Regional Office for the Western Pacific; 2016.

23. Barate P, Temmerman M. Why Do Mothers Die? The Silent Tragedy of Maternal Mortality. Current Women's Health Reviews. 2009;5(4):230-8. 
24. Jacobs C, Moshabela M, Maswenyeho S, Lambo N, Michelo C. Predictors of Antenatal Care, Skilled Birth Attendance, and Postnatal Care Utilization among the Remote and Poorest Rural Communities of Zambia: A Multilevel Analysis. Frontiers in Public Health 2017, 5(11).

25. Mohan D, Gupta S, LeFevre A, Bazant E, Killewo J, Baqui AH. Determinants of postnatal care use at health facilities in rural Tanzania: multilevel analysis of a household survey. BMC Pregnancy Childbirth. 2015;15:282.

26. Akibu M, Tsegaye W, Megersa T, Nurgi S. Prevalence and Determinants of Complete Postnatal Care Service Utilization in Northern Shoa, Ethiopia. J Pregnancy. 2018;2018:8625437.

27. Tesfaye G, Chojenta C, Smith R, Loxton D. Magnitude and correlates of postnatal care utilization among reproductive aged women in a rural district in eastern Ethiopia: A cross-sectional study. Midwifery. 2019;70:22-30.

28. Singh K, Brodish P, Haney E. Postnatal care by provider type and neonatal death in sub-Saharan Africa: a multilevel analysis. BMC Public Health. 2014;14:941.

\section{Figures}

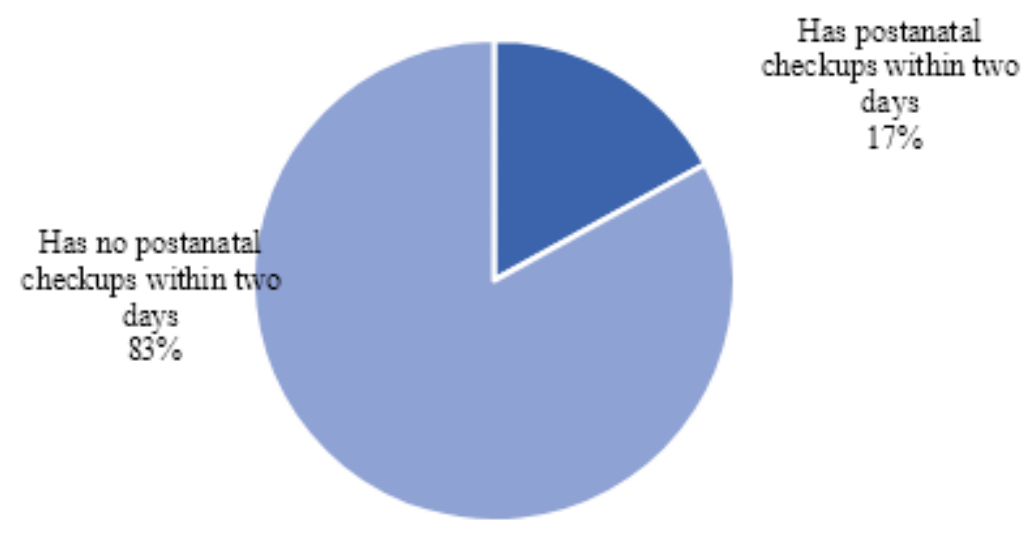

\section{Figure 1}

Prevalence of postnatal checkups within two days among the respondents in Ethiopia. 